\title{
Analysis of viscoelastic fluid flow in different geometries abrupt contraction
}

\author{
Ameen Ibrahim Galeel ${ }^{\dagger}$, Khudheyer S. Mushatet ${ }^{\ddagger}$ and Hussam Ali Khalif ${ }^{\dagger}$. \\ ${ }^{\dagger}$ Mechanical engineering, Thi-Qar university, Said Dakhil- Nasiriyah -Thi-Qar-Iraq. \\ ${ }^{\ddagger}$ Mechanical engineering, Thi-Qar university, Bathah- Nasiriyah -Thi-Qar-Iraq.
}

In this work, two-dimension incompressible laminar viscoelastic fluid flow in an expansion-contraction duct has been investigated numerically. The effect of expansion-contraction shape, Deborah number, Reynolds number, expansion ratio and contraction length on the flow field variables has been investigated. Four cases for the expansion-contraction duct configurations are tested, the first case is the expansion duct, the second case is the contraction-expansion duct, the third case is the triangular expansion-contraction duct and the fourth case is the twoside triangular expansion-contraction duct. The study investigated the effect of the parameters: Reynolds number (Re), Deborah number (De), contraction length and expansion ratio (ER) on the flow field variables (pressure, stresses and velocity).

The FENE-P (Finitely Extensible Nonlinear Elastic in the Peterlin approximation) viscoelastic fluid model is chosen for the modeling of viscoelastic fluid flow. The code is written in Simply Fortran 2 computer language. Numerically the momentum equations and the FENE-P model equation are solved by using the finite volume method passed on the collocated grid arrangement by using the Rhie-Chow interpolation. The power low scheme is used for the convective terms in the momentum equations, the up-wind scheme is used in the convective terms in the FENE-P model equation and the TDMA algorithm is used to solve the algebraic equations.

The results show that the expansion ratio when decreasing causes an increase in the stresses and the pressure for all the studied cases. Further, the contraction length increment playing a major effect on the increasing of the pressure. It is discovered that increasing contraction length by 50\% causes an increase in the pressure by 50\%. For Deborah number, the results show that Deborah number effects all variables in the flow field, where the stresses show increasing with the increasing of Deborah number at the expansion side of all the cases. Moreover, the pressure is also increased as Deborah number increase for all the cases. The expansion duct it shows that increasing Deborah number from 0 to 1 causes an increase of $1.2 \%$ of the pressure, while for the contraction-expansion duct this percentage is increased. It is shown that increasing Deborah from 0 to 0.5 causes an increasing by $5 \%$ of the pressure. Furthermore, the effect of Deborah number on the recirculation zones is to shrink their size for all the cases.

A comparison between the studied cases are presented and shows that the contraction-expansion duct has the maximum stresses and maximum required pressure, while the triangle contraction-expansion has the smallest required pressure. The limit of Deborah number gets to 1.2 in the expansion duct, while it is limited to 0.5 for the other cases.

Keywords: FENE-P constitutive equation; Expansion flows; Finite-volume method; Viscoelasticity; Collected grid. 


\section{NOMENCLATURE:}

\begin{tabular}{|l|l|l|}
\hline Symbol & Meaning & Units \\
\hline $\mathrm{H}$ & $\begin{array}{l}\text { Half height of } \\
\text { the channel }\end{array}$ & $\mathrm{m}$ \\
\hline $\mathrm{u}$ & X-axis velocity & $\mathrm{m} / \mathrm{s}$ \\
\hline $\mathrm{v}$ & Y-axis velocity & $\mathrm{m} / \mathrm{s}$ \\
\hline $\mathrm{P}$ & pressure & $\mathrm{N} / \mathrm{m} 2$ \\
\hline $\mathrm{De}$ & Deborah number & ----- \\
\hline $\operatorname{Re}$ & $\begin{array}{l}\text { Reynolds } \\
\text { number }\end{array}$ & ---- \\
\hline
\end{tabular}

\section{GREEK SYMBOLS:}

\begin{tabular}{|c|l|l|}
\hline Symbol & Meaning & Units \\
\hline$\rho$ & density & $\mathrm{Kg} / \mathrm{m} 3$ \\
\hline$\tau_{x x}$ & X-axis stress & $\mathrm{N} / \mathrm{m} 2$ \\
\hline$\tau_{y y}$ & Y-axis stress & $\mathrm{N} / \mathrm{m} 2$ \\
\hline$\tau_{x y}$ & Shear stress & $\mathrm{N} / \mathrm{m} 2$ \\
\hline$\lambda$ & Relaxation time & ----- \\
\hline$\phi$ & General variable & ----- \\
\hline$\Gamma$ & $\begin{array}{l}\text { Diffusion } \\
\text { coefficient }\end{array}$ & ---- \\
\hline$\nabla$ & Divergence signs & ---- \\
\hline
\end{tabular}

\section{ABBREVIATION:}

\begin{tabular}{|l|l|}
\hline Abbreviation & Meaning \\
\hline FVM & Finite volume method \\
\hline FEM & Finite element method \\
\hline
\end{tabular}

\begin{tabular}{|l|l|}
\hline CV & Control volume \\
\hline UCM & $\begin{array}{l}\text { Upper convicted } \\
\text { Maxwell }\end{array}$ \\
\hline FENE-P & $\begin{array}{l}\text { Finitely Extensible } \\
\text { Nonlinear Elastic in the } \\
\text { Peterlin approximation }\end{array}$ \\
\hline FENE-CR & $\begin{array}{l}\text { Finitely Extensible } \\
\text { Nonlinear Elastic by } \\
\text { Chilcott and Rallison }\end{array}$ \\
\hline TDMA & $\begin{array}{l}\text { Tri-Diagonal Matrix } \\
\text { Algorithm fluid }\end{array}$ \\
\hline CFD & $\begin{array}{l}\text { Computational } \\
\text { dynamics }\end{array}$ \\
\hline E & East \\
\hline W & West \\
\hline S & South \\
\hline $\mathrm{N}$ & north \\
\hline
\end{tabular}

\section{Introduction:}

The viscoelastic fluid is a non-Newtonian fluid that behaves as a viscous-fluid and elastic material, polymers, organic material, tooth best, honey and other material are an example of viscoelastic fluids. The manufacturing processes that involve polymers such as extrusion and injection molding are an example of a viscoelastic fluid flow.

The flow of viscoelastic fluids in an expansion or contraction ducts have a major application in plastic manufacturing. The injection molding and extrusion manufacturing methods are examples of contraction and expansion flow. In which the plastic material is in the liquid state is a type of viscoelastic fluids. Also, the flow of these fluids in the mold's cavity inside the injection machine molds is an important consideration of viscoelastic flow, where a study most concern with that. 
The study of viscoelastic fluid flow in different flow system is studied over a wide range of literatures.

Abdelkader et al. (2017) [1] studied the forced convection heat transfer for viscoelastic fluid with the FENE-P model by using the finite element method in ANSYS-poly-flow code. Their work was concern with the flowing between two plates, the lower plate having a grove of a rectangular shape. They tested deferent parameters like the aspect ratio of the cavities (AR =0.25,0.5), Reynolds number (25,250,500), fluid elasticity (Wi) and the extensibility parameter of the model $(\ell)$. They observed that increasing of Weissenberg number leads to change in the size of the generated vortices within the cavity for $(\mathrm{Wi}<=5)$ and change in the stream line characteristics by a generation of a single vortex with the cavity section for high $(\mathrm{Wi}>5)$ also a progressive change in the thermal layers especially in the cavity area.

Afonso1 et al. (2011) [2] performed a numerical study for the high level of elasticity problems. They utilized the log-conformation method to simulate the high Weissenberg numbers problems. Two case of flow they was considered ,The flow through a twodimensional (2D) $4: 1$ abrupt contraction and $4: 1$ three-dimensional square-square abrupt contraction. The 2D case was restricted to the Oldroyd-B constitutive equation and the $3 \mathrm{D}$ dimensional case was for both the Oldroyd-B and Phan-Thien-Tanner (PTT) fluids by using the finite volume numerical method for a collocated grid arrangement. For the 2D case They concluded that the flow became unstable at De equal about 2.5 and when increasing De number the fluid exhibit a local unsteadiness which seems to grow as elasticity increased For the $4: 1$ squaresquare 3D abrupt contraction. Very high Deborah numbers were attained $(D e \approx 20$ for the PTT model with $\varepsilon=0.02$ and $D e \approx 10000$ for the PTT model with $\varepsilon=0.25$ ), with prediction of strong vortex enhancement and inversion of the sense of rotation of fluid particles inside the vortices.

Chunquan Fu1 et al. 2010 [3] numerically studied The flow of the differential upper-convected Maxwell (UCM) flowing in contraction channel by using the finite volume method passed on staggered grid arrangement. The hybrid scheme was used for the velocities in the momentum equations, and the upwind scheme was used for the stresses in the constitutive equations. Reynolds number was holed at $\mathrm{Re}=0.00001$, while the Weissenberg from 0 to 3 . It was found that the viscoelasticity of the polymer solutions was the main factor affecting the sweep efficiency when increasing the elasticity levels. It was shown that the flow area in the corner was enlarged smoothly. This shows that the sweep area and displacement efficiency increase as the elasticity increases also the pressure drop in the corner area was increased as the elasticity levels increased.

FU Chun-quan et al. (2008) [4] studied a numerical simulation by using the finite volume method on staggered grid arrangement for the UCM viscoelastic fluid model flowing through a 4:1 planer expansion. They used the upwind scheme for the viscoelastic stresses and the hybrid scheme for the momentum equations. The flow parameters were as follows; Reynolds number equal to 0.00001 and Weissenberg numbers from 0 to 2 . They observed that with increasing the elasticity levels the recirculation zones became smaller, sweep area and displacement efficiency were increased.

Kerim Yapici.et al. (2009) [5] numerically studied the laminar flow of viscoelastic fluid obeying Oldryed-B model flowing in a lid-driven cavity in 2D case by using the finite volume method passed on collocated grid arrangement. They used the central difference scheme (CD) for the momentum equations and the first order upwind scheme for the viscoelastic stresses. A range of both Reynolds number and Weissenberg number was studied.

It was shown that the size of recirculation zones was decreased with increasing of Weissenberg number at creeping flow $(\operatorname{Re}=0.01)$ or small Reynolds number $(\operatorname{Re}=100)$. Also, it was shown that the first normal stress differences was increased with the increasing of Weissenberg number.

Oliveira.et al. (2005) [6] numerically examined the flow of viscoelastic fluid with FENE-CR model flowing past a circular cylinder positioned symmetrically in a channel flow have a blockage ratio of 0.5 . They have used the finite volume method as a numerical method for the solution of the governing equation on a collocated grid arrangement. Reynolds number was equal to 0.1 , and Deborah number (1-10). Their simulation shows that at 
De $>1.3$ an $\ell 2=144$ the flow becomes unsteady and the drag coefficient tends to increase with Deborah number and take sinusoidal variation with time at $\mathrm{De}=1.5$. The study extends to test the effect of the extensibility parameter $\ell 2$ so they take another value for this parameter $\ell 2=100$ and the simulations show similar results. The variations happened in a large Deborah number De $=2.5$.

In the current work a simulation done for the viscoelastic fluid obeying the FENE-P model flow in four cases of duct configuration (expansion, contraction-expansion, rectangular-contraction and two side rectangular contraction). In these cases the effect of expansion ratio, contraction length, Deborah number and Reynolds number are investigated.

The governing equations and the FENE-P viscoelastic model equations both are solved by using the finite volume method passed on a collocated grid. The code is written by simply Fortran 2 computer language.

\section{Problem Description}

The physical domain consist of a contractionexpansion configuration. Four cases for this configuration are studied as follows:

1. Expansion

2. Expansion- Contraction

3. Expansion With Triangle contraction

4. Two Side Triangle Contraction-Expansion

The information about each model are given in Table.1.

The study is concentrated on the effect of channel shape, Reynolds number and Deborah number on the pressure increment and stresses distribution in the flow field. Where the flow considered to be, Viscoelastic fluid, Steady, Laminar, Two dimensional, and the Gravity is neglected .

Tabel.1. The considered models.

\begin{tabular}{|l|l|}
\hline Shape & $\begin{array}{l}\text { Dimension } \\
\text { in } \mathbf{m}\end{array}$ \\
\hline
\end{tabular}

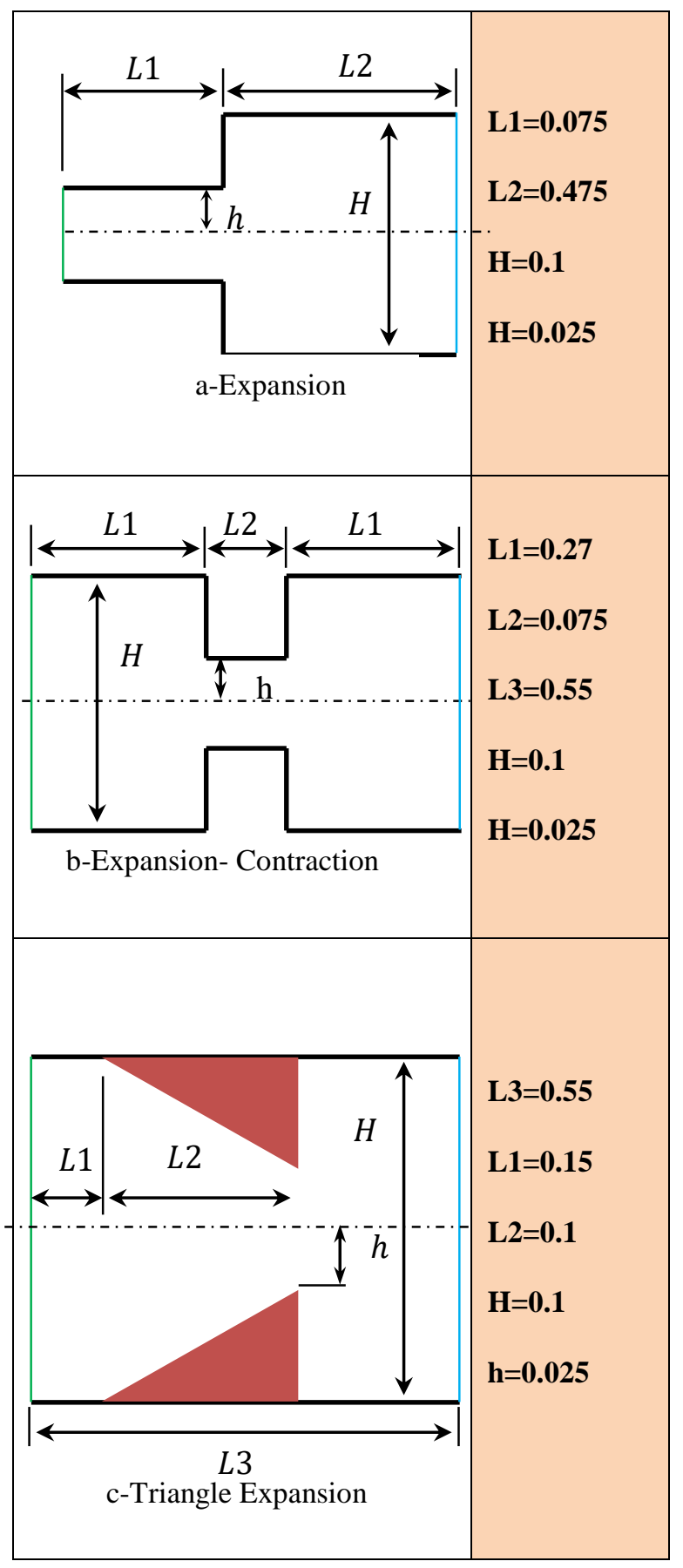




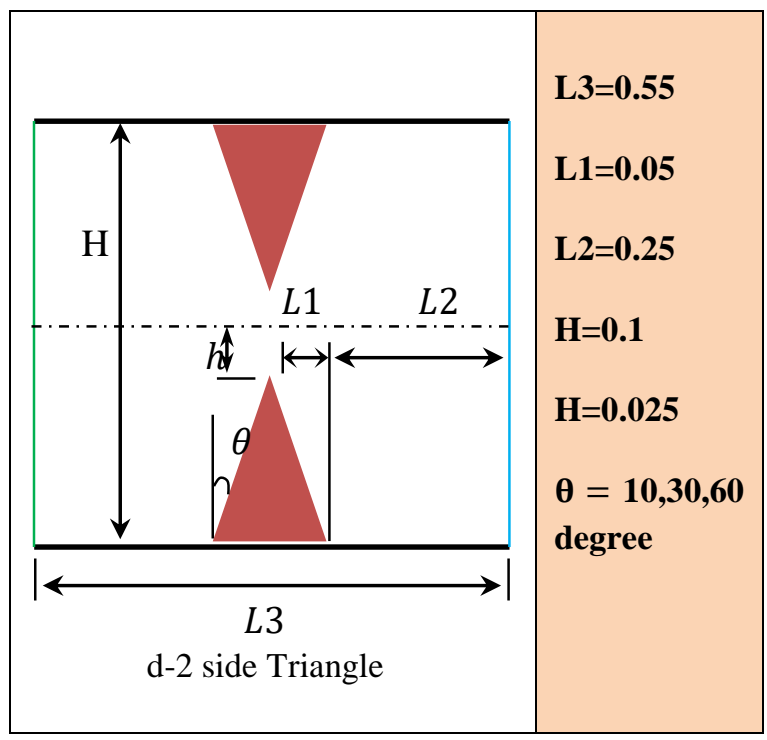

The Governing Equations

The governing equations that describes the flow of viscoelastic fluid for the FENE-P model for two dimensional ,steady ,laminar and incompressible fluid are; the mass and momentum conservation laws coupled with the viscoelastic FENE-P model which are non-linear ,partial differential equations. In cartesian form:

The continuity equation[7]:

$\frac{\partial u}{\partial x}+\frac{\partial v}{\partial y}=0$

The momentum equation in general form: $\mathrm{X}$-momentum:

$$
\begin{aligned}
& \frac{\partial}{\partial x}(\rho u u)+\frac{\partial}{\partial y}(\rho v u) \\
& =-\frac{\partial p}{\partial x}+\frac{\partial \tau_{x x}}{\partial x} \\
& +\frac{\partial \tau_{x y}}{\partial y}
\end{aligned}
$$

Y-momentum:

$$
\begin{aligned}
& \frac{\partial}{\partial x}(\rho u v)+\frac{\partial}{\partial y}(\rho v v) \\
& =-\frac{\partial p}{\partial x}+\frac{\partial \tau_{y y}}{\partial y} \\
& +\frac{\partial \tau_{x y}}{\partial x}
\end{aligned}
$$

And the FENE-P viscoelastic model [8]:

$$
\begin{aligned}
& \lambda_{f}\left(u \frac{\partial \tau_{x x}}{\partial x}+v \frac{\partial \tau_{x x}}{\partial y}-2 \tau_{x x} \frac{\partial u}{\partial x}-2 \tau_{x y} \frac{\partial u}{\partial y}\right)+f \tau_{x x} \\
& =2 a \eta_{p} \frac{\partial u}{\partial x} \\
& \lambda_{f}\left(u \frac{\partial \tau_{y y}}{\partial x}+v \frac{\partial \tau_{y y}}{\partial y}-2 \tau_{y y} \frac{\partial v}{\partial y}-2 \tau_{x y} \frac{\partial v}{\partial x}\right)+f \tau_{y y} \\
& =2 a \eta_{p} \frac{\partial v}{\partial y} \\
& \lambda_{f}\left(u \frac{\partial \tau_{x y}}{\partial x}+v \frac{\partial \tau_{x y}}{\partial y}-\tau_{x x} \frac{\partial v}{\partial x}-\tau_{x y} \frac{\partial u}{\partial x}-\tau_{x y} \frac{\partial v}{\partial y}\right. \\
& \left.-\tau_{y y} \frac{\partial u}{\partial y}\right)+f \tau_{x y} \\
& =a \eta_{p}\left(\frac{\partial u}{\partial y}\right. \\
& \left.+\frac{\partial v}{\partial x}\right)
\end{aligned}
$$

$f$

$$
\begin{gathered}
=1 \\
+\frac{3 a+\frac{\lambda_{f}}{\eta_{p}}\left(\tau_{x x}+\tau_{y y}\right)}{\ell^{2}} \\
a=\frac{1}{1-\frac{3}{\ell^{2}}}
\end{gathered}
$$

Where:

$u=$ is the $\mathrm{x}$-direction velocity component, $v=$ is the $\mathrm{y}$-direction velocity component, $P=$ is the hydrostatic pressure, $\tau_{x x}=$ is the normal stress in $\mathrm{x}$-direction, $\tau_{y y}=$ is the normal stress in y-direction, $\tau_{x y}=$ is the shear stress, $\rho=$ is the density, $\lambda_{f}=$ is the relaxation time parameter for the viscoelastic fluid, $\eta_{p}=$ is the polymer contribution viscosity, and $\ell=$ is the extensibility parameter of the model.

The dimensionless numbers:

Reynolds number $(\operatorname{Re})[7]$ :

$$
R e=\frac{\rho U H}{\mu}
$$

Deborah number (De)[5]:

$$
D e=\frac{\lambda U}{H}
$$

\section{The Boundary Condition}


Three types of boundary conditions:

\section{1- Inlet Boundary Condition}

The inlet boundary condition represent the entrance of flow variable to the flow domain. A fully developed inlet velocity to the domain is assumed:

$$
u=U\left(1-\frac{y}{H}\right)^{2}
$$

Where , $u$ is the axial velocity , $U$ is the average velocity, $H$ is the hight of the entrance and $y$ is the $y$ direction coordinate normal to $u$. Other variable as follows :

The vertical velocity component :

$$
v=0
$$

The stresses are got numerically when the following values are supped into the qunstitutive equations:

$$
\begin{array}{ccc}
u=U\left(1-\frac{y}{H}\right)^{2} & \frac{\partial u}{\partial x}=0 \quad \frac{\partial u}{\partial y} \\
& =2 U\left(1-\frac{y}{H}\right) \\
v=0 & \frac{\partial v}{\partial x}=0 \quad \frac{\partial v}{\partial y}=0
\end{array}
$$

\section{2-Outlet Boundary Condition}

At outlet the flow is assumed to reaches the fully developed flow so the axial velocity and other variable would not be changed with the direction of the flow:

$$
\begin{aligned}
\frac{\partial u}{\partial x}=0 \quad \frac{\partial v}{\partial x}=0 \quad & \frac{\partial \tau_{x x}}{\partial x}=0 \quad \frac{\partial \tau_{y y}}{\partial x} \\
=0 & \frac{\partial \tau_{x y}}{\partial x}=0
\end{aligned}
$$

As these equation solved at the exit numerically the following equations can be get :

$$
u_{e}=u_{e-1} \quad v_{e}=v_{e-1}
$$

Where $u_{e}$ Is the velocity at the exit boundary and $u_{e-1}$ Is the velocity before the exit boundary by one mesh. The same for the stresses:

$$
\tau_{x x e}=\tau_{x x e-1} \quad \tau_{x y e}=\tau_{x y e-1} \quad \tau_{y y e}
$$

\section{3-Wall Boundary Condition}

Wall boundary is the most common boundary condition in fluid flow problem, it represent any object in the flow where no flow in it. The appropriate representation for this type of boundary condition is the no slip condition where the velocity component are both zero, so at the boundary:

$$
\begin{array}{rlrl}
u=0 & v=0 \\
\frac{\partial u}{\partial x}=0 & \frac{\partial v}{\partial x}=0
\end{array}
$$

If these values supped in the constitutive equation then :

1- For the wall parallel to $\mathrm{x}$-axis

In such situations the flow obeys the conditions $u=v=0 ; \frac{\partial u}{\partial x}=\frac{\partial v}{\partial x}=0 ; \quad$ and from the continuity equation $\frac{\partial v}{\partial y}=0$. Incorporating these conditions in the constitutive equations yields a set of three equations with three unknowns which upon resolution give on the boundary:

$$
\tau_{x x}=2 \lambda \mu\left(\frac{\partial u}{\partial y}\right)^{2} \quad \tau_{y y}=0 \quad \tau_{x y}=2 \mu\left(\frac{\partial u}{\partial y}\right)
$$

2- For the wall parallel to y-axis In similar way:

$$
\tau_{x x}=0 \quad \tau_{y y}=2 \lambda \mu\left(\frac{\partial v}{\partial x}\right)^{2} \quad \tau_{x y}=2 \mu\left(\frac{\partial v}{\partial x}\right)
$$

\section{The Numerical Analyses}

\section{Discretization Of Momentum Equations}

The momentum equations (1) and (2) before the discretization, first they are written in the general form by adding a diffusion term for both the sides of the momentum equations[19].

$$
\begin{aligned}
& \frac{\partial}{\partial x}(\rho u u)+\frac{\partial}{\partial y}(\rho v u) \\
& =\frac{\partial}{\partial x}\left(\mu \frac{\partial u}{\partial x}\right)+\frac{\partial}{\partial y}\left(\mu \frac{\partial u}{\partial y}\right)-\frac{\partial P}{\partial x}+\frac{\partial \tau_{x x}}{\partial x}+\frac{\partial \tau_{x y}}{\partial y} \\
& -\frac{\partial}{\partial x}\left(\mu \frac{\partial u}{\partial x}\right) \\
& -\frac{\partial}{\partial y}\left(\mu \frac{\partial u}{\partial y}\right) \\
& \frac{\partial}{\partial x}(\rho u v)+\frac{\partial}{\partial y}(\rho v v) \\
& =\frac{\partial}{\partial y}\left(\mu \frac{\partial v}{\partial y}\right)+\frac{\partial}{\partial x}\left(\mu \frac{\partial v}{\partial x}\right)-\frac{\partial P}{\partial y}+\frac{\partial \tau_{y y}}{\partial y}+\frac{\partial \tau_{x y}}{\partial x} \\
& -\frac{\partial}{\partial y}\left(\mu \frac{\partial v}{\partial y}\right) \\
& -\frac{\partial}{\partial x}\left(\mu \frac{\partial v}{\partial x}\right)
\end{aligned}
$$


Where $\mu$ is the Newtonian contribution viscosity.

The diffusion term is added because there are no diffusion terms in the momentum equation and well known that diffusion terms are essential to promote the stability of finite-volume schemes when applied to transport equations [6].

The integration is done over the nodal point $\mathrm{P}$ as shown in Fig.5,so by integration the governing equation (3) and (4) by using the divergence theorem for the convective and diffusion terms ;

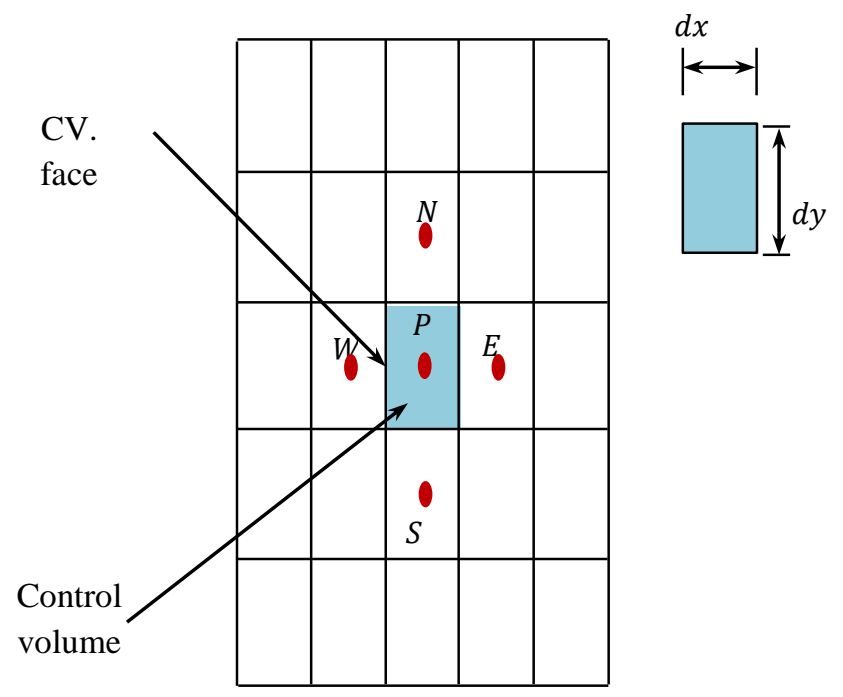

Fig.1.Grid shape and distribution for the computational domain.

$$
\begin{aligned}
\int_{V_{p}}\left(\frac{\partial}{\partial x}(\rho u u)+\right. & \left.\frac{\partial}{\partial y}(\rho v u)\right) d V \\
& =\int_{V_{p}}\left(\frac{\partial}{\partial x}\left(\mu \frac{\partial u}{\partial x}\right)+\frac{\partial}{\partial y}\left(\mu \frac{\partial u}{\partial y}\right)\right) d V \\
& +\int_{V_{p}} S_{x} d V
\end{aligned}
$$

The flow rates $F_{e}, F_{w}, F_{n}$ And $F_{s}$ Are calculated across the face of the control volume, the diffusion coefficient and the peclet number are given in table.4.

Table.2. The mass flux, diffusion conductance and peclet number.

\begin{tabular}{|c|c|c|}
\hline The $\begin{array}{r}\text { flow } \\
\text { rates }\end{array}$ & The $\begin{array}{r}\text { diffusion } \\
\text { coefficient }\end{array}$ & The $\begin{array}{r}\text { peclet } \\
\text { number }\end{array}$ \\
\hline$F_{e}=(\rho u A)_{e}$ & $D_{e}=\frac{\mu A_{x}}{\delta x}$ & $P_{w}=\frac{F_{w}}{D_{w}}$ \\
\hline $\begin{array}{l}F_{w} \\
=(\rho u A)_{w}\end{array}$ & $D_{w}=\frac{\mu A_{x}}{\delta x}$ & $P_{n}=\frac{F_{n}}{D_{n}}$ \\
\hline$F_{n}=(\rho v A)_{n}$ & $D_{n}=\frac{\mu A_{y}}{\delta y}$ & $P_{s}=\frac{F_{s}}{D_{s}}$ \\
\hline$F_{s}=(\rho v A)_{s}$ & $D_{s}=\frac{\mu A_{y}}{\delta y}$ & \\
\hline
\end{tabular}

The function $A\left(\left|P_{i}\right|\right)$ For power low scheme is [8]:

$A\left(\left|P_{i}\right|\right)$

$=\operatorname{Max}[0,(1$

$\left.-0.1|P|)^{5}\right]$

The discretization of the source term:

The algebraic equations results from the numerical integration for the momentum equations are:

$$
\begin{gathered}
A_{P} u_{P}=A_{W} u_{W}+A_{E} u_{E}+A_{N} u_{N}+A_{S} u_{S} \\
+b \\
\begin{array}{c}
A_{P} v_{P}=A_{W} v_{W}+A_{E} v_{E}+A_{N} v_{N}+A_{S} v_{S} \\
+b
\end{array}
\end{gathered}
$$

The coefficients for these equations are given in Table 3.

Table 3. The coefficients of the $x$ and y momentum equations.

\begin{tabular}{|l|l|l|l|}
\hline \multicolumn{1}{|l|}{$\begin{array}{l}\text { For } \\
\text { equation }\end{array}$} & \multicolumn{1}{l|}{-momentum } & \multicolumn{1}{l|}{$\begin{array}{l}\text { Yor } \\
\text { equation }\end{array}$} \\
\hline \multirow{6}{*}{$A_{P}$} & $D_{e} A\left(\left|P_{e}\right|\right)$ & & $D_{e} A\left(\left|P_{e}\right|\right)$ \\
& $+\operatorname{Max}\left[F_{e}, 0\right]$ & & $+\operatorname{Max}\left[F_{e}, 0\right]$ \\
& $+D_{w} A\left(\left|P_{w}\right|\right)$ & & $+D_{w} A\left(\left|P_{w}\right|\right)$ \\
& $+\operatorname{Max}\left[-F_{w}, 0\right]$ & & $+\operatorname{Max}\left[-F_{w}, 0\right]$ \\
& $+D_{n} A\left(\left|P_{n}\right|\right)$ & $A_{P}$ & $+D_{n} A\left(\left|P_{n}\right|\right)$ \\
& $+\operatorname{Max}\left[F_{n}, 0\right]$ & & $+\operatorname{Max}\left[F_{n}, 0\right]$ \\
& $+D_{s} A\left(\left|P_{s}\right|\right)$ & & $+D_{s} A\left(\left|P_{s}\right|\right)$ \\
& $+\operatorname{Max}\left[-F_{s}, 0\right]$ & & $+\operatorname{Max}\left[-F_{s}, 0\right]$ \\
& $-S_{P} V_{P}$ & & $-S_{P} V_{P}$ \\
& & & \\
\hline
\end{tabular}




\begin{tabular}{|c|c|c|c|}
\hline$A_{W}$ & $\begin{array}{l}D_{w} A\left(\left|P_{w}\right|\right) \\
+\operatorname{Max}\left[F_{w}, 0\right]\end{array}$ & $A_{W}$ & $\begin{array}{l}D_{w} A\left(\left|P_{w}\right|\right) \\
+\operatorname{Max}\left[F_{w}, 0\right]\end{array}$ \\
\hline$A_{E}$ & $\begin{array}{l}D_{e} A\left(\left|P_{e}\right|\right) \\
+\operatorname{Max}\left[-F_{e}, 0\right]\end{array}$ & $A_{E}$ & $\begin{array}{l}D_{e} A\left(\left|P_{e}\right|\right) \\
+\operatorname{Max}\left[-F_{e}, 0\right]\end{array}$ \\
\hline$A_{S}$ & $\begin{array}{l}D_{s} A\left(\left|P_{S}\right|\right) \\
+\operatorname{Max}\left[F_{S}, 0\right]\end{array}$ & $A_{S}$ & $\begin{array}{l}D_{S} A\left(\left|P_{S}\right|\right) \\
+\operatorname{Max}\left[F_{s}, 0\right]\end{array}$ \\
\hline$A_{N}$ & $\begin{array}{l}D_{n} A\left(\left|P_{n}\right|\right) \\
+\operatorname{Max}\left[-F_{n}, 0\right]\end{array}$ & $A_{N}$ & $\begin{array}{l}D_{n} A\left(\left|P_{n}\right|\right) \\
+\operatorname{Max}\left[-F_{n}, 0\right]\end{array}$ \\
\hline$b$ & $S_{x} V_{P}$ & $b$ & $S_{y} V_{P}$ \\
\hline
\end{tabular}

\section{Discretization Of The Constitutive Equations}

The constitutive equations contain convective terms only for the primitive variable,so divergence theorem used for the convective terms only. The scheme used for the face value of the stress in the convective terms is the up-wind scheme which is of first order.

For the $\mathrm{x}$-axis constitutive equation:

$\lambda_{f}\left(u \frac{\partial \tau_{x x}}{\partial x}+v \frac{\partial \tau_{x x}}{\partial y}-2 \tau_{x x} \frac{\partial u}{\partial x}-2 \tau_{x y} \frac{\partial u}{\partial y}\right)+f \tau_{x x}$

$=2 a \eta_{p} \frac{\partial u}{\partial x}$

After integration, arrangement and putting everything together:

$$
\begin{gathered}
A_{P} \tau_{x x P}=A_{W} \tau_{x x W}+A_{E} \tau_{x x E}+A_{N} \tau_{x x N}+A_{S} \tau_{x x S} \\
+b
\end{gathered}
$$

The same way for the other two equations.

\section{The Solution Algorithm}

As mentioned before that the solution algorithm is followed on the SIMPLE algorithm with the required adjustment so it can be used for the viscoelastic equations and for the collocated grid arrangement instead of the staggered arrangement. The steps of the solution algorithm for the code as follows:

1- Set initial guess for the variables $v, u, p$ and $\rho$

2- Solve the momentum equations for $v$ and $u$

3- Compute the face velocity by using Rhie Chow interpolation

4- Solve the pressure correction equation
5- Correction for the variable $v, u$ and $p$

6- Solve the constitutive equations for $\tau_{x x}, \tau_{y y}$ and $\tau_{x y}$

7- Set the current values of the variables as an initial values

8- Check if the solution converged or not if yes stop if no go back to first step and repeat until converges

\section{Grid Independency}

In order to get grid independence solution, a number of cases are studied using different mesh sizes. In these cases, the pressure variation is used to test the grid independence. The results showed that the solution is reached grid independence at the mesh size $200 \times 100$.

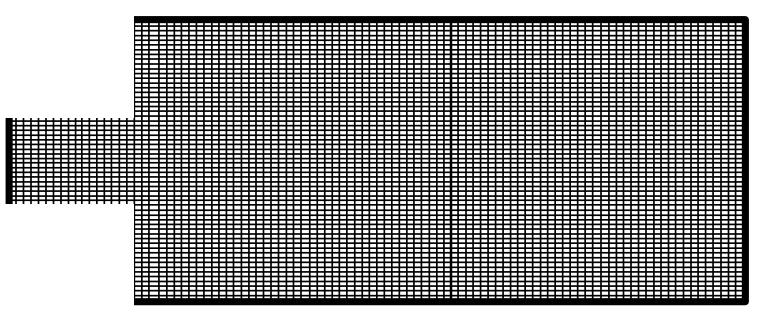

Fig.2. The grid intensity $200 \times 100$.

\section{Results}

The results are divided to sub cases. Each subcase is concern with the effect of one parameter such as the expansion ratio, Deborah number and Reynolds number effects. In Fig.17 the contours for the x-axis stress are shown for all the case at $\mathrm{Re}=1$ and $\mathrm{De}=0.5$. 
A comparsion between the studied cases is presented.Fig.18 shows the center line $\tau_{x x}$ stress with the length of the duct for a different duct expansion

\section{A- Effect Of Expansion Ratio}
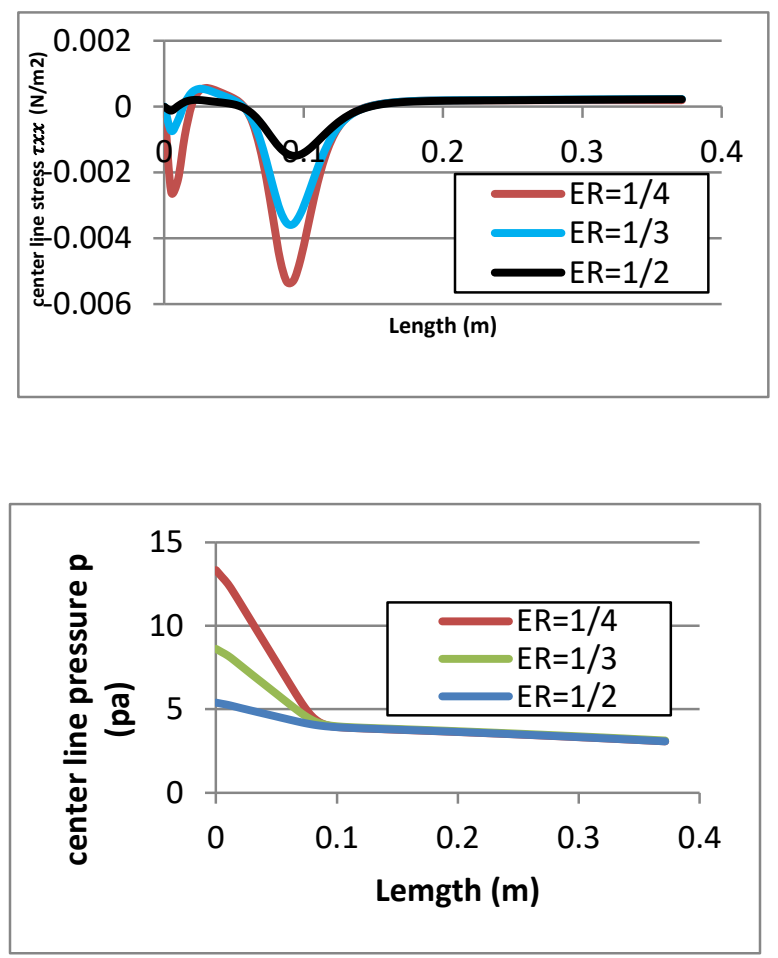

Fig.3 (a) variation of $x$-axis stress with the expansion ratio and (b) variation of pressure with the expansion ratio for the expansion at $\mathrm{Re}=1, \mathrm{De}=0.5$ and $\mathrm{Lc}=0.75$.

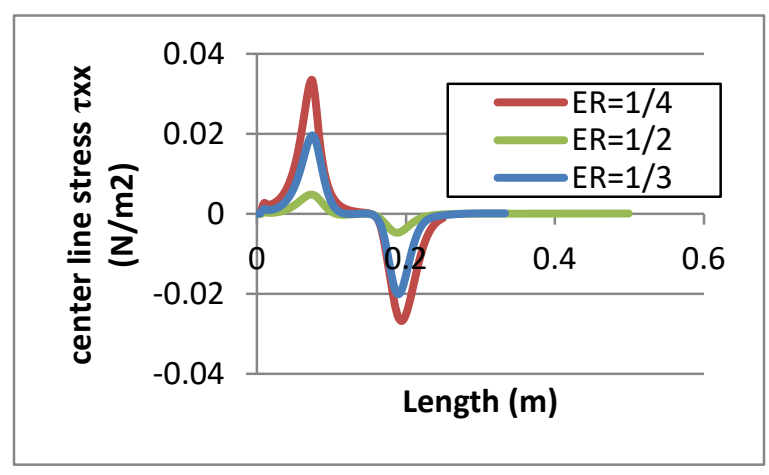

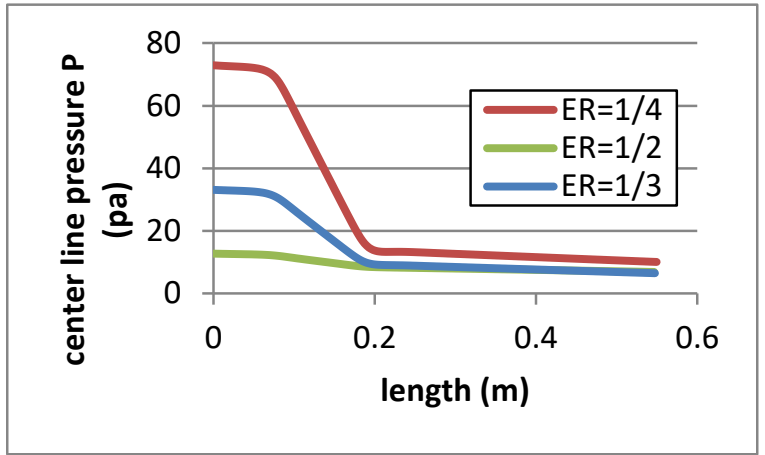

Fig.4 (a) variation of $x$-axis stress with the expansion ratio and (b) variation of pressure with the expansioncontraction ratio for the expansion at $\mathrm{Re}=1, \mathrm{De}=0.5$ and $\mathrm{I} c=0.75$.
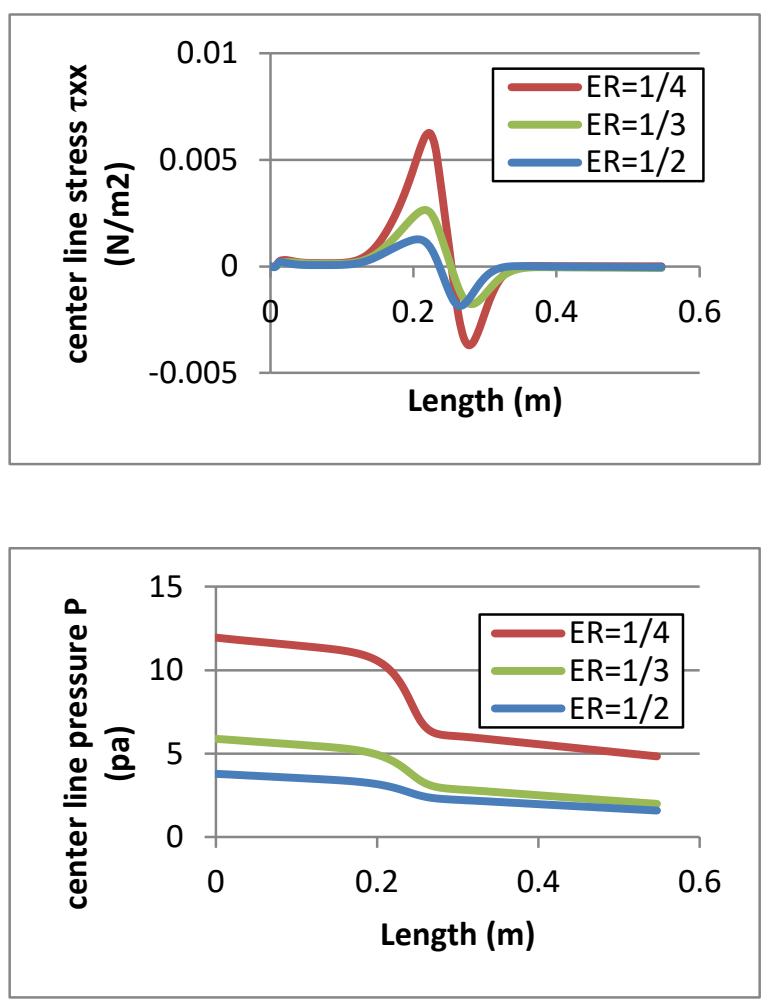

Fig.5 (a) variation of $\mathrm{x}$-axis stress with the expansion ratio and (b) variation of pressure with the triangle expansion ratio for the expansion at $\mathrm{Re}=1, \mathrm{De}=0.5$ and $\mathrm{Lc}=0.75$. 

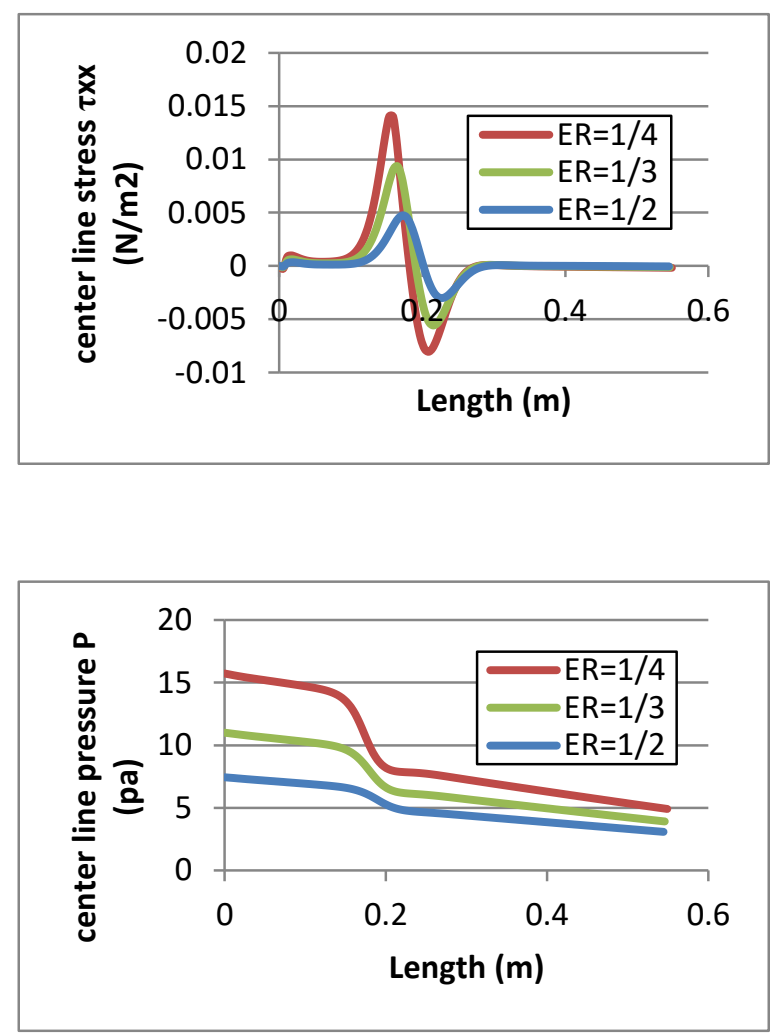

Fig.6 (a) variation of $x$-axis stress with the expansion ratio and (b) variation of pressure with the expansion ratio for the two side traingle expansion at $\mathrm{Re}=1, \mathrm{De}=0.5$ and $\mathrm{Lc}=0.75$.

\section{B-Effect of upstream length}

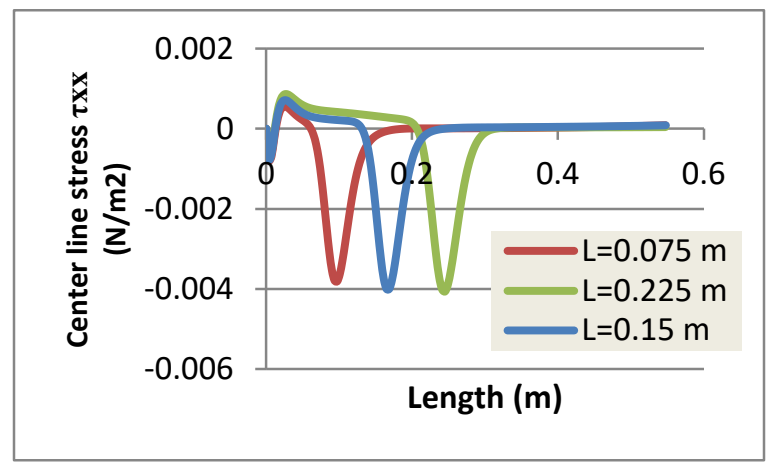

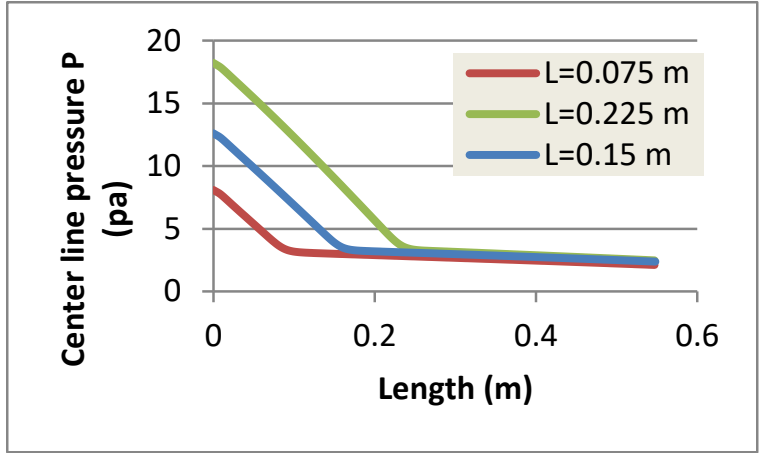

Fig.7(a) variation of $x$-axis stress with the contraction length and (b) variation of pressure with contraction length for the expansion at $\mathrm{Re}=1, \mathrm{De}=0.5$ and $\mathrm{Lc}=0.75$.
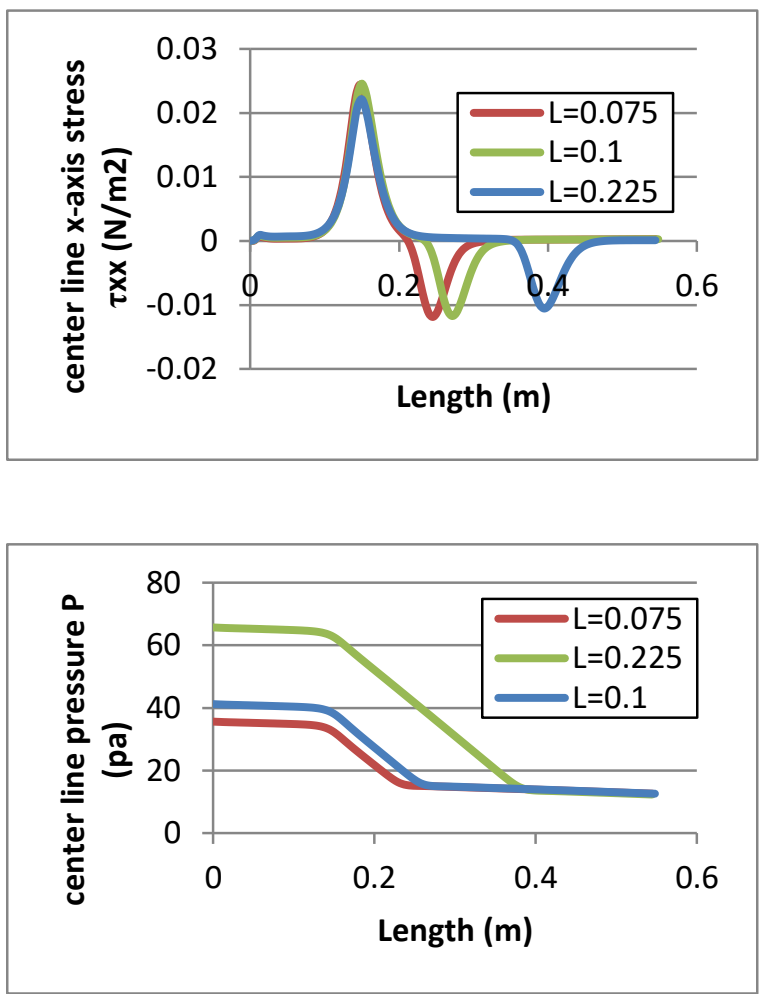

Fig.8(a) variation of $\mathrm{x}$-axis stress with the contraction length and (b) variation of pressure with contraction length for the expansion-contraction at $\mathrm{Re}=1, \mathrm{De}=0.5$ and $\mathrm{I} c=075$ 


\section{C-Effect of Deborah Number}
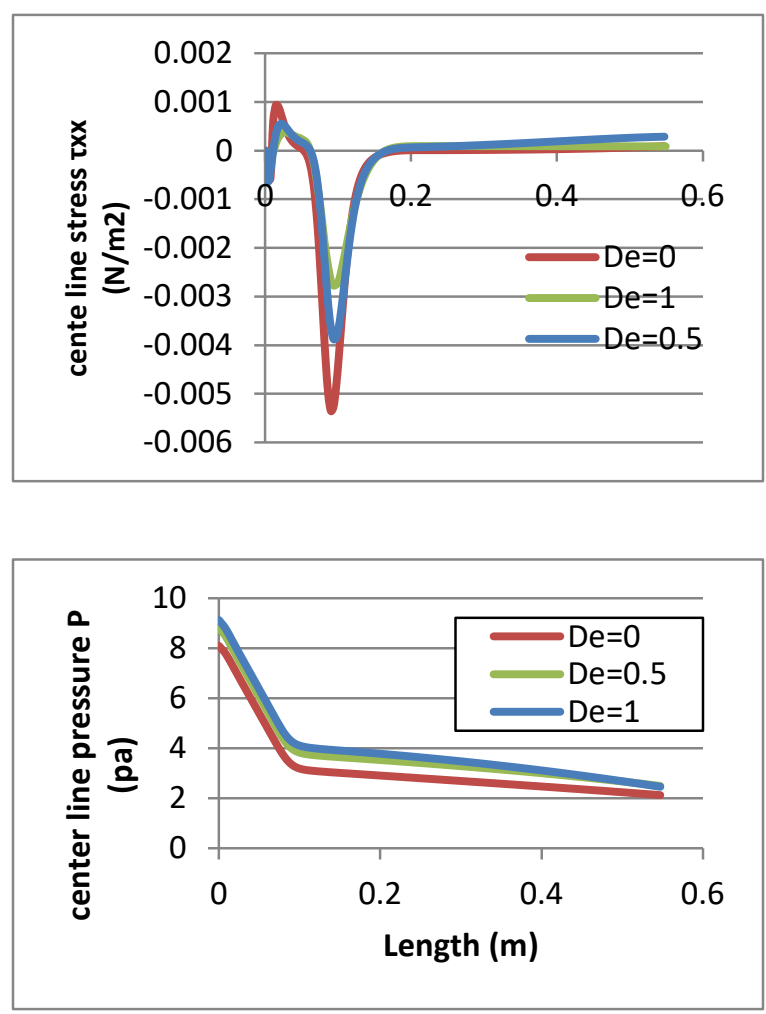

Fig.9 (a) variation of $x$-axis stress with the Deborah number and (b) variation of pressure with Deborah number for the expansion at $\mathrm{Re}=1, \mathrm{ER}=0.3$ and $\mathrm{Lc}=0.75$.

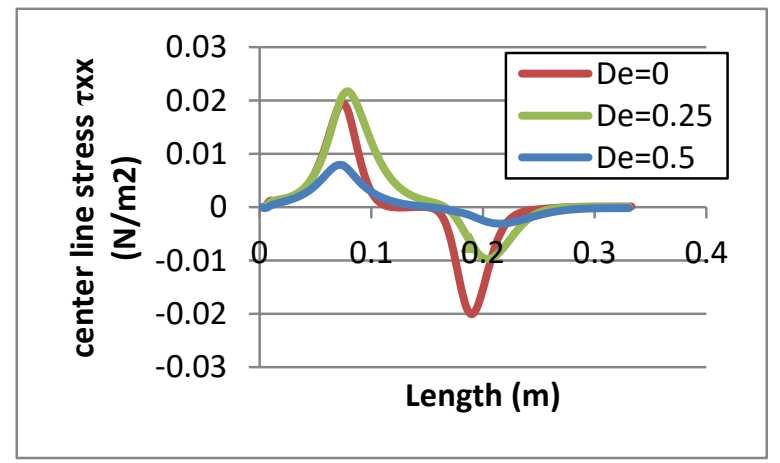

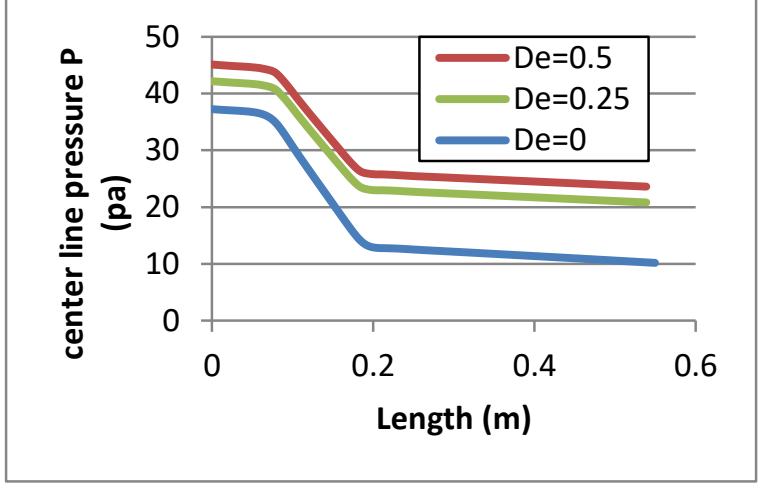

Fig.10 (a) variation of x-axis stress with the Deborah number and (b) variation of pressure with Deborah number for the expansion-contraction at $\mathrm{Re}=1, \mathrm{ER}=0.3$ and $\mathrm{Lc}=0.75$.
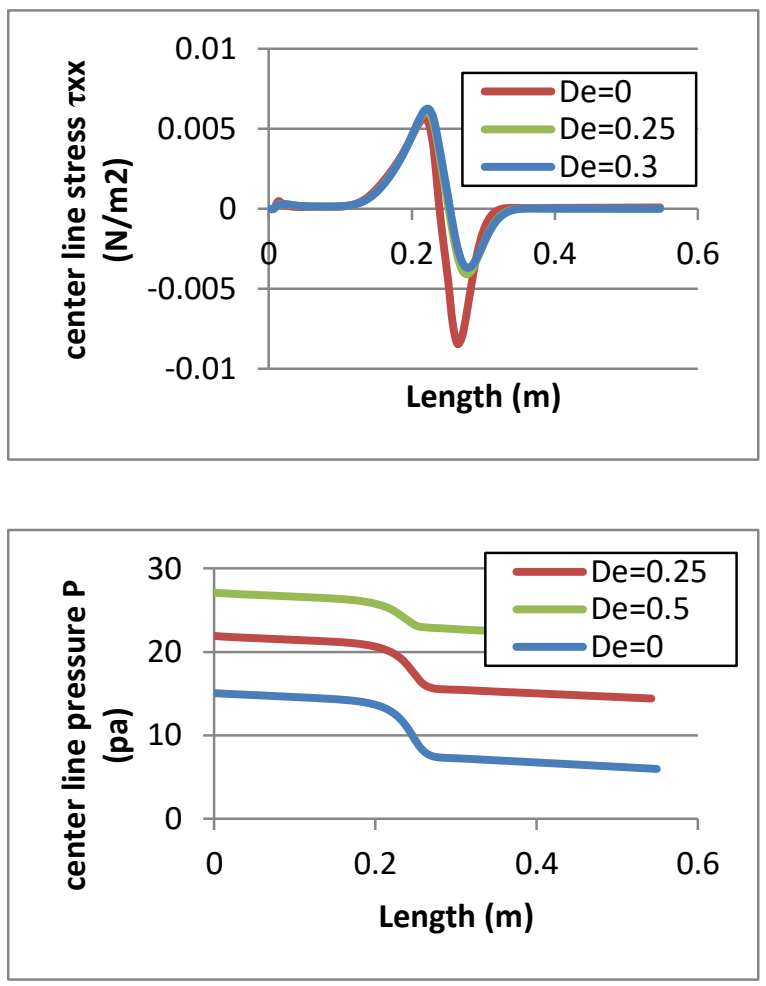

Fig.11 (a) variation of $\mathrm{x}$-axis stress with the Deborah number and (b) variation of pressure with Deborah number for the traingle expansion at $\mathrm{Re}=1, \mathrm{ER}=0.3$ and $\mathrm{Lc}=0.75$. 


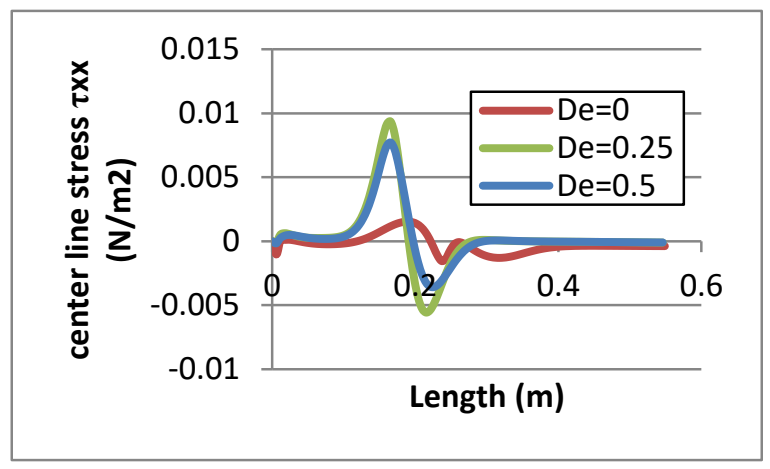

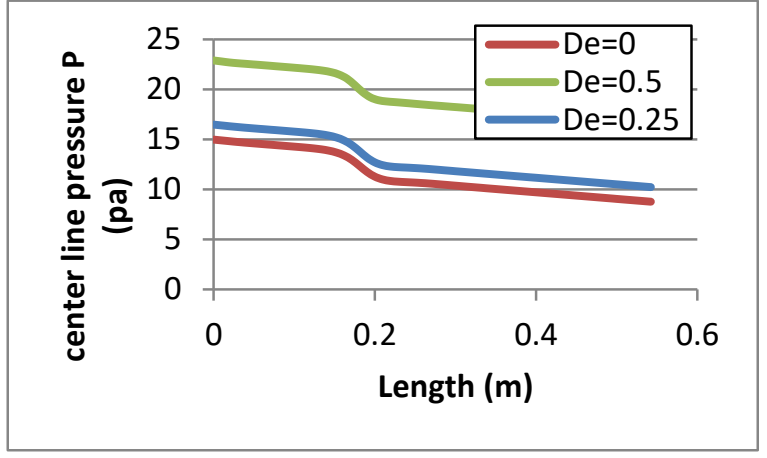

Fig.12 (a) variation of $x$-axis stress with the Deborah number and (b) variation of pressure with Deborah number for the two side triangle expansion at $\mathrm{Re}=1, \mathrm{ER}=0.3$ and $\mathrm{Lc}=0.75$.

\section{D-Effect Of Reynolds Number}

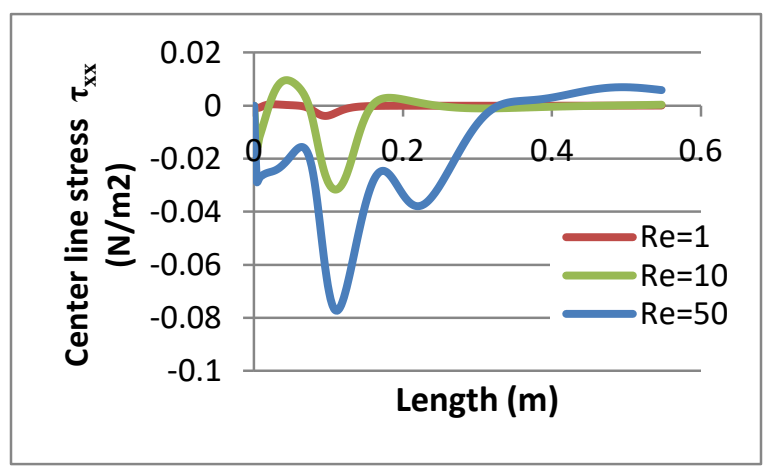

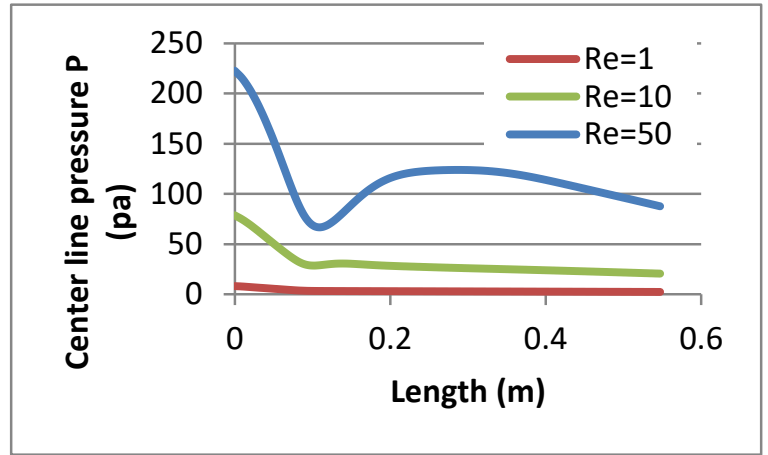

Fig.13 (a) variation of $\mathrm{x}$-axis stress with the Reynolds number and (b) variation of pressure with Reynolds number for the expansion at $\mathrm{De}=0.3, \mathrm{ER}=0.3$ and $\mathrm{Lc}=0.75$.
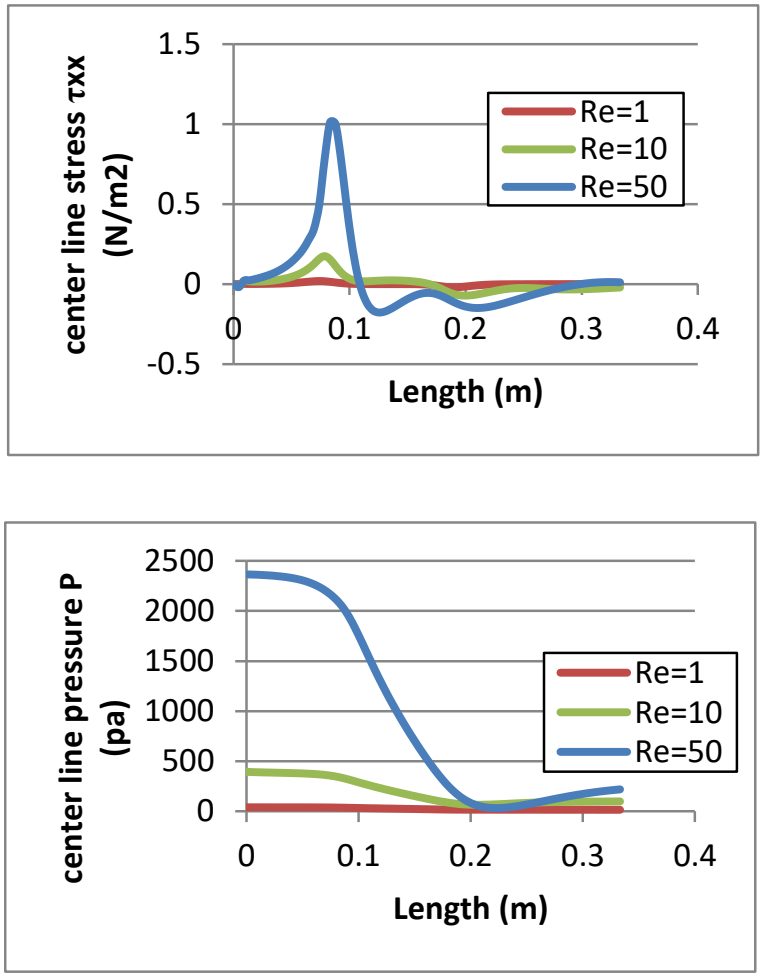

Fig.14 (a) variation of $\mathrm{x}$-axis stress with the Reynolds number and (b) variation of pressure with Reynolds number for the expansion-contraction at $\mathrm{De}=0.3, \mathrm{ER}=0.3$ and $\mathrm{Lc}=0.75$. 

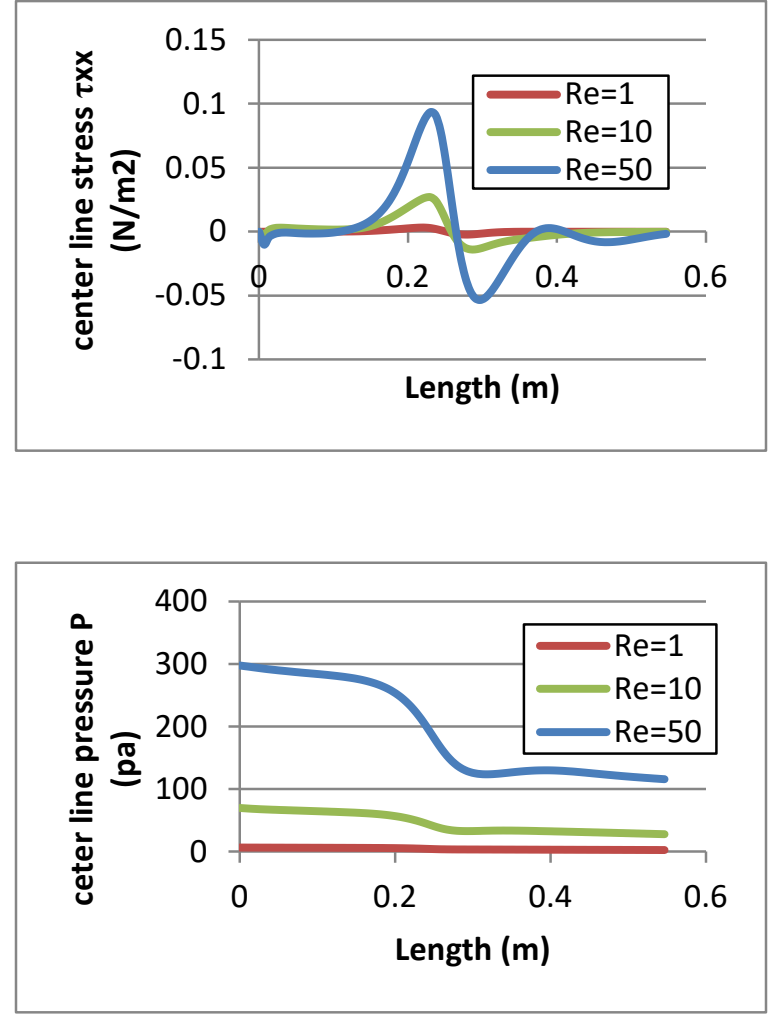

Fig.15 (a) variation of $x$-axis stress with the Reynolds number and (b) variation of pressure with Reynolds number for the traingle expansion at $\mathrm{De}=0.3, \mathrm{ER}=0.3$ and $\mathrm{Lc}=0.75$.

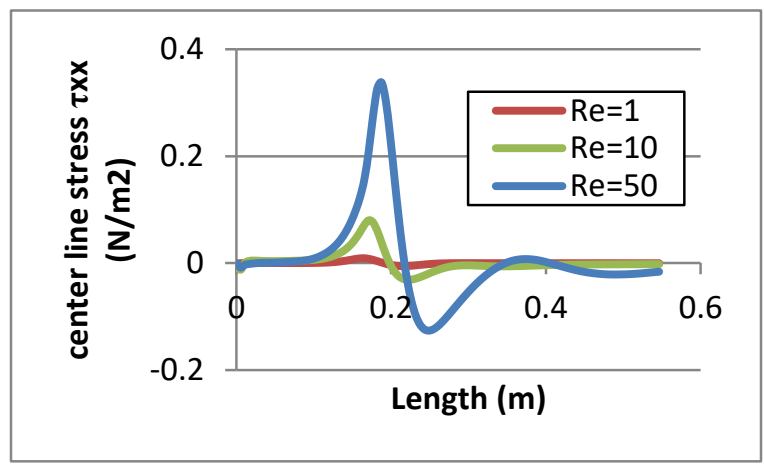

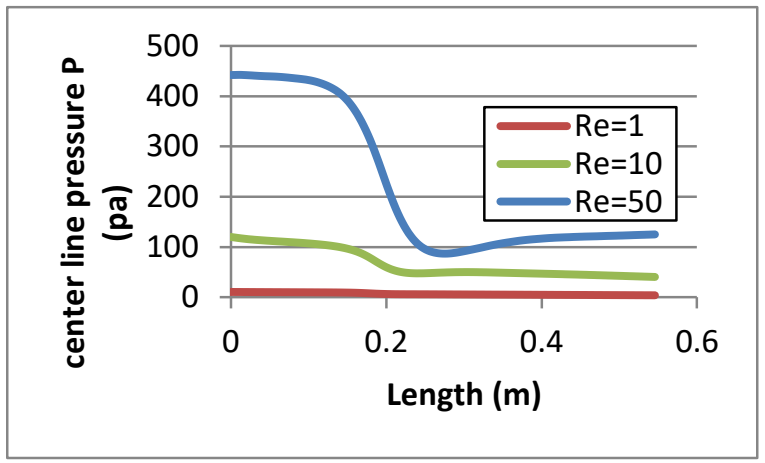

Fig.16 (a) variation of $x$-axis stress with the Reynolds number and (b) variation of pressure with Reynolds number for the two side triangle expansion at $\mathrm{De}=0.3, \mathrm{ER}=0.3$ and $\mathrm{Lc}=0.75$.

In Fig.17 the contours for the $\mathrm{x}$-axis stress are shown for all the case at $\mathrm{Re}=1$ and $\mathrm{De}=0.5$.
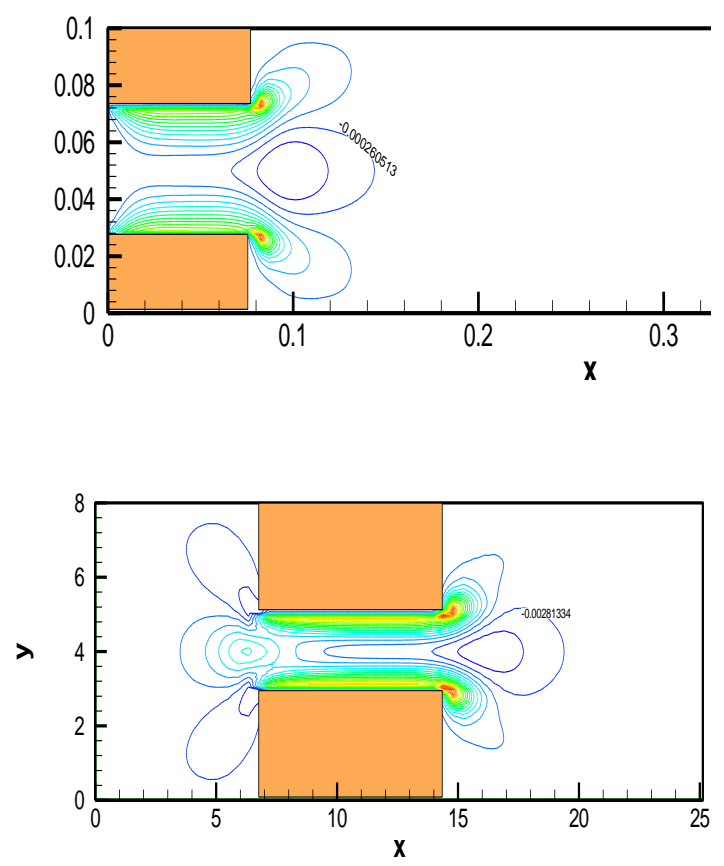

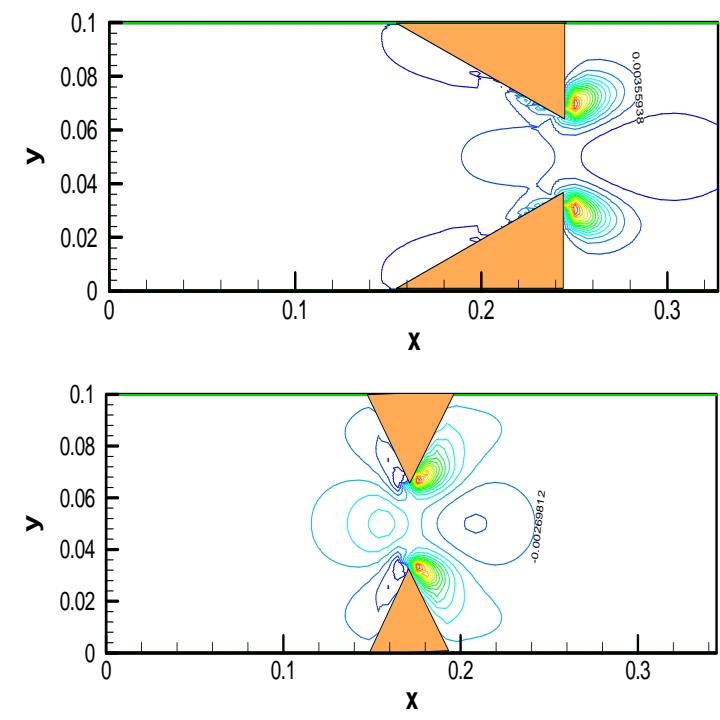

Fig.17 the contours of $x$-axis for each case at $\mathrm{Re}=1$ and $\mathrm{De}=0.5$.

Fig. 17 represents the shapes at $\mathrm{Re}=1, \mathrm{De}=0.5$, $\mathrm{L}=0.08$, and $\mathrm{ER}=1 / 3$. The figure shows that the expansion-contraction have the largest normal stress at the contraction, and the lowest one is the expansion. All the curves start and end for the same point. This can be explained because the contractionexpansion shape has a large velocity gradient because of the contraction and has more dynamic pressure losses with four corners which makes a real obstacle for the flow of the fluid, so at this region, the fluid gets higher stress. For the expansion can be explained that the expansion begins with a small flow rate. The duct diameter at the beginning is small compared to other shapes and this shape also have only two corners that generate vortices.

Fig.5 shows the center line pressure with the length of the duct for different expansion shape at $\mathrm{Re}=1, \mathrm{D}=0.5$, and $\mathrm{ER}=1 / 3$. The figure demonstrates that the contraction-expansion shape is the higher value. It is mean that this shape requires the largest pressure to force the fluid in the duct. The same explanation for this behavior of the contractionexpansion and the expansion as it explained in the normal stress.

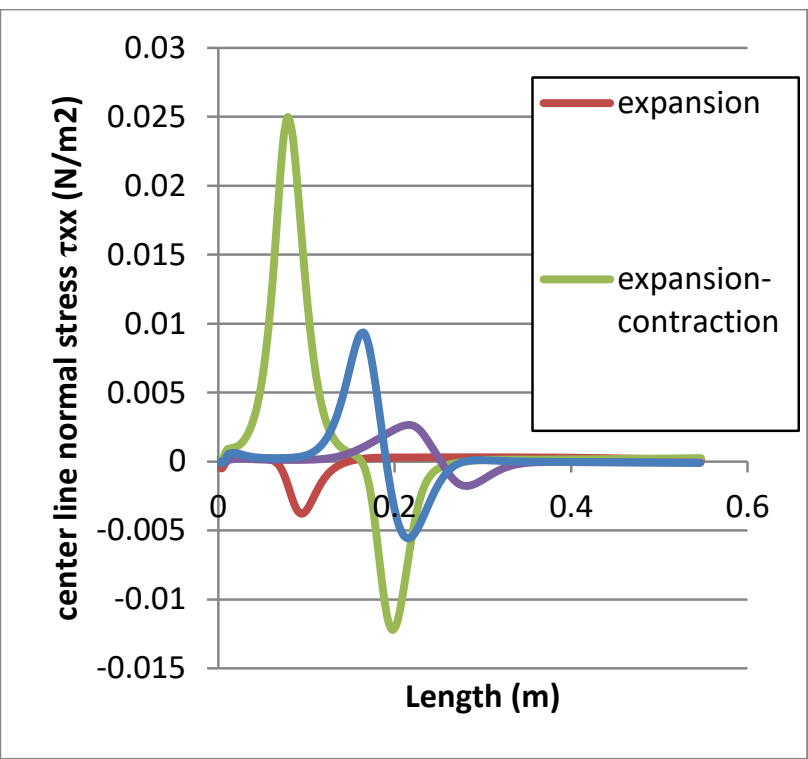

Fig.18 The normal stress $\tau_{x x}$ at the center line of the duct with the length of the duct for different shapes at $\mathrm{Re}=1, \mathrm{De}=0.5$ And $\mathrm{ER}=1 / 3$.

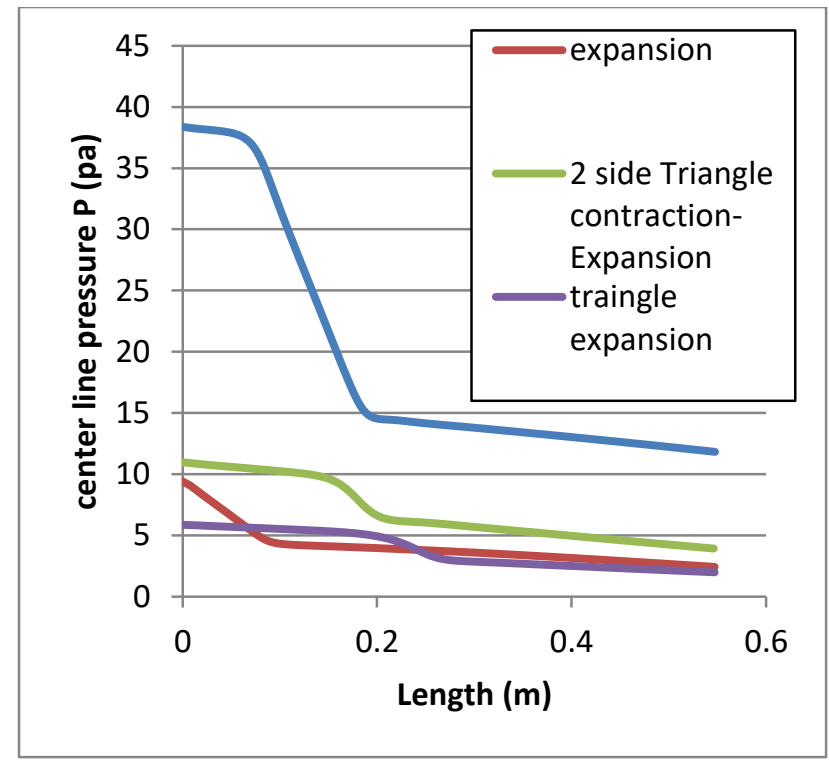

Fig.19 The pressure at the center line of the duct with the length of the duct for different shapes at $\mathrm{Re}=1, \mathrm{De}=0.5$ And $\mathrm{ER}=1 / 3$.

Further, the maximum value of Deborah number reached at case 1 is 1.2 , while it is limited to 0.5 for the other cases. 


\section{Conclusion}

The study has been done in this work and the discussion brings the following conclusion points:

1- The vortices size of the recirculation zones that generated in the corner of the expansion and the contraction is reduced as Deborah number is increases.

2- The stresses $\tau_{x x}, \tau_{y y}$ And $\tau_{x y}$ for the viscoelastic fluid are increased as Deborah number is increases.

3- The pressure is increased when Deborah number increases. There is $1.2 \%$ increasing in the pressure when Deborah increases from 0 to 1 for the expansion duct, and 5\% increasing when Deborah increases from 0 to 0.5 for the contraction-expansion duct.

4- The contraction-expansion duct it has the largest stresses and greatest pressure required, while the expansion duct was the smallest one for the stresses and the triangle expansion had the smallest inlet pressure.

5- The largest value of Deborah number was reached in the expansion duct case $(\mathrm{De}=1.2)$, while it was limited to 0.5 for the reaming cases.

6- The largest pressure drop is found with the contraction-expansion duct and the smallest one is with the two side triangle contraction duct.

7- The stress $\tau_{x x}$ is decreased as the expansion ratio decreased for the expansion side of all the cases, and the reverse behavior for $\tau_{y y}$, which is increased as the expansion ratio decreased. The reverse behavior of the stresses is observed for the contraction side for all the cases.

8- At all the cases the pressure is increased with the decreasing of the expansion ratio.

9- Large decreasing of $\tau_{x x}$ stress and increasing of $\tau_{y y}$ with the increasing of Reynolds number at the expansion side for all the cases, and increasing of $\tau_{x x}$ stress while decreasing of $\tau_{y y}$ for the contraction side for all the cases.
10- Large increasing in the pressure with the increasing of Reynolds number for all the cases.

11- The pressure and stresses are decreased with the increasing of angle $\theta$ for the fourth case.

12- The contraction length causes reduction in the size of the vortices generated in the corners.

\section{References}

[1] R.P. Chhabra And J.F. Richardson. NonNewtonian Fluid And Applaied Rehology. Wales, Swansea, Bh, 2008.

[2] Philippe Nghe. Flows Of Complex Fluids In Micro Geometries. France, Paris University, 2009

[3] Comminal, Raphael Benjamin. Numerical Simulation Of Viscoelastic Freesurface Flows Using A Streamfunction/Logconformation Formulation And

The Volumeoffluid Method. Technical University Of

Denmark, Technical University Of Denmark, 2015

[4] Michel O. Deville And Thomas B. Gatski. Mathematical Modeling For Complex Fluids And

Flows. Norfolk, Usa, Springer, 2012.

[5] K.A. Missirlis A, D. Assimacopoulos A, E. Mitsoulis. A Finite Volume Approach In The Simulation Of Viscoelastic Expansion Flows. Athens, Athens 157 -80, Greece, Elsever, 1998.

[6] Abdelkader Filali, Lyes Khezzar* And Mohamed Saeed Alshehhi. Numerical Simulation Of Fene-P Viscoelastic Fluids Flow And Heat Transfer In Grooved Channel With Rectangular Cavities. Abu Dhabi 2533, United Arab Emirates, Springer, 2017 
[7] Junfeng Yang. Numerical Study Of PolymerInduced Drag Reduction In Flow Past Circular Cylinder. Imperial College, London, Sw7 2az, Uk , S.N., 2015.

[8] A. M. Afonso1, P. J. Oliveira2. Dynamics Of High-Deborah-Number Entry Flows:A Numerical Study. Porto, Portugal, Cambridge University Press , 2011.

[9] Chunquan Fu1, Hongliang Zhou2, Hongjun Yin1. Flow Behavior Of Ucm Viscoelastic Fluid In Sudden Contraction Channel. Beijing, China, Natural Science, 2010.

[10] Fu Chun-Quan,Jiang Hai-Mei. Finite Volume Method For Simulation Of Viscoelastic Flow Through A Expansion Channel. Daqing 163001, China, Elsever, 2008.

[11] Kerim Yapicia, Bulent Karasozenb, Yusuf Uludaga. Finite Volume Simulation Of Viscoelastic Laminar Flow In A Lid-Driven Cavity. Ankara, Turkey, Elsever, 2009.

[12] Paulo J. Oliveira A, *, Am Ilcar I.P. Miranda. A Numerical Study Of Steady And Unsteady Viscoelastic Flow Past Bounded Cylinders. Covilh a, Portugal, Elsever, 2005.

[13] Raanan Fattala, Raz Kupfermanb.TimeDependent Simulation Of Viscoelastic Flows At High Weissenbergnumber Using The Log-Conformation Representation. Jerusalem 91904, Israel, Elsever, 2005 .

[14] Manuel A. Alvesa, Paulo J. Oliveira. On The Effect Of Contraction Ratio In Viscoelastic Flowthrough Abrupt Contractions . Guimar̃aes, Portugal, Elsevier, 2004.
[15] Paulo J. Oliveira. Asymmetric Flows Of Viscoelastic Fluids In Symmetric Planar Expansion Geometries. Covilhã, Portugal, Elsevier, 2003.

[16] Manuel A. Alves A, Paulo J. Oliveira. Benchmark Solutions For The Flow Of Oldroyd-B And Ptt Fluids In Planar Contractions. Porto, Portugal, Elsevier, 2003.

[17] Paulo J. Oliveira*. Method For Time-Dependent Simulations Of Viscoelastic Flows:Vortex Shedding Behind Cylinder. Covilhã, Portugal, Elsevier, 2001.

[18] M.A. Alves , F.T. Pinho , P.J. Oliveira. The Flow Of Viscoelastic Fluids Past A Cylinder: Finite-

Volume High-Resolution Methods . Covilhã,

Portugal, Elsevier, 2001.

[19] P.J. Oliveira A, F.T. Pinho. Numerical Simulation Of Non-Linear Elastic Flows With A General Collocated Finite-Volume Method. Codex, Portugal, Elsevier, 1998.

[20] Costas D. Dimitropoulosa, R. Sureshkumar. Direct Numerical Simulation of Viscoelastic Turbulent Channel Flow Exhibiting Drag Reduction: Effect Of The Variation Of Rheological Parameters - Newark, Elsevier, 1998.

[21] J. Azaiez, R. Gu6nette, A. Ait-Kadi. Numerical Simulation Of Viscoelastic Flows Through A Planarcontraction. Quebec, Canada, Elsevier, 1995.

[22] M.S. Dar-Wish And J.R. Whiteman. Numerical Modelling Of Viscoelastic Liquids Using A FiniteVolume Method. Brunei University, Elsevier, 199

[23] R.J. Poole A,*, M.A. Alves B, P.J. Oliveira. Plane Sudden Expansion Flows Of Viscoelastic Liquids. Braga, Portugal, Elsevier, 2007. 
[24] R. Keunings And M.J. Crochet. Numerical Simulation Of The Flow Of A Fluid Through An Abrupt Contraction *. Amsterdam, Elsevier, 1984

[25] L. Khezzar 1, A. Filali, M. Alshehhi. Flow And Heat Transfer Of Fene-P Fluids In Ducts Of Various Shapes:Effect Of Newtonian Solvent Contribution.

United Arab Emirates, Elsevier, 2014.

[26] Robert E. Gaidos * And Ron Darby. Numerical Simulation And Change In Type In The Developing Flow Of A Nonlinearviscoelastic Fluid. Amsterdam , Elsevier, 1988.

[27] Plane Sudden Expansion Flows Of Viscoelastic Liquids. Portigual, Elsevier, 2007.

[28] Cedric Chauviere A, Alexei Lozinski. Simulation Of Dilute Polymer Solutions Using A Fokker-Planck Equation. Lausanne, Switzerland, Elsevier, 2004

[29] P. J. Oliveira. An Exact Solution For Tube And Slit Flow Of A Fene-P Fluid. Covilhg,, Portugal, Springer, 2002.

[30]S ao Carlos, Brasil, S.N., 2005.

[31] A. R. Muniz, A. R. Secchi. High-Order Finite Volume Method For Solving Viscoelastic Fluid Flows

- Brazil, S.N., 2008.

[32] P. Saramito. Efficient Simulation Of Nonlinear Viscoelastic Fluid Flows. Grenoble Cedex, France , Elsevier, 1995.

[33] Nhan Phan-Thien, Hua-Shu Dou.Viscoelastic Flow Past A Cylinder: Drag Coe $\bullet$ Cient. Australia , Elsevier, 1999.
[34] P.Y. Huang, J. Feng. Wall Effects On The Flow Of Viscoelastic Fluids Around A Circular Cylinder.

Mmneapolis, Elsevier, 1995.

[35] Wan-Chi Tsai A, Gregory H. Miller. Numerical Simulations of Viscoelastic Flow In Complex Geometries Using A Multi-Mode Giesekus Model.

United States, Elsevier, 2014.

[36] Nasir Ali A 1. Theoretical Analysis Of The Exiting Thickness Of Sheets In The Calendering Of Fene-P Fluid. Nilore, Islamabad 44000, Pakistan,

Elsevier, 2015.

[37] Suhas V. Patankar. Numerical Heat Transfear And Fluid Flow. Usa, Mcgraw-Hill, 1980.

[38] Suhas. V. Patankar. Computation Of Conduction And Duct Flow Heat Transfear. Usa, Mcgraw-Hill , 1991.

[39] F. Moukalled - L. Mangani. The Finite Volume Method In Computational Fluid Dynamics . American University Of Beirut, Springer, 2015.

[40] $H \quad K$ Versteeg And $W$ Malalasekera. An Introduction To Computational Fluid Dynamics.

Usa, Pearson, 2007.

[41] Yunus Çengel. F L U I D ME CHA N I C S Fundamentals And Applications. United States Of America, Mcgraw-Hill, 2013.

[42] W. P. Graebel. Advanced Fluid Mechanics. Michigan, Elsevier, 2007.

[43] R.R. Huilgol And N. Phan-Thien. Fluid Mechanics Of Viscoelasticity. Aberystwyth, U.K., Elsevier, 1997. 
[44] Pieter Wesseling. Principles Of C Omputational

F Luid Dynamics. Netherlands, Springer, 2009.

[45] Raphaele Herbin And Dietmar Kroner. Finite

Volumes For Complex Applications Iii. S.L.,

Kogan Page Science, 2003. 